\title{
Histological Aspects of Skeletal Muscle Fibers Splitting of C57BL/6NCrl Mice
}

\author{
Peter MAKOVICKÝ ${ }^{1}$, Pavol MAKOVICKÝ ${ }^{2}$ \\ ${ }^{1}$ Czech Centre for Phenogenomics, Institute of Molecular Genetic of the Czech Academy of \\ Sciences, Vestec, Czech Republic. ${ }^{2}$ Department of Biology, Faculty of Education, J. Selye \\ University, Komarno, Slovak Republic
}

Received July 1, 2019

Accepted November 28, 2019

Epub Ahead of Print March 23, 2020

\begin{abstract}
Summary
The objective of the current study is to present data on the splitting of skeletal muscle fibers in $\mathrm{C} 57 \mathrm{BL} / 6 \mathrm{NCrl}$ mice. Skeletal muscles ( $m$. rectus femoris ( $m$. quadriceps femoris)) from 500 (250 $\circ$ and 250 o) C57BL/6NCrl mice in the 16th week of life were sampled during autopsy and afterwards standardly histologically processed. Results show spontaneous skeletal muscle fiber splitting which is followed by skeletal muscle fiber regeneration. One solitary skeletal muscle fiber is split, or is in contact with few localized splitting skeletal muscle fibers. Part of the split skeletal muscular fiber is phagocytosed, but the remaining skeletal muscular fiber splits are merged into one regenerating skeletal muscle fiber. Nuclei move from the periphery to the regenerating skeletal muscle fiber center during this process. No differences were observed between female and male mice and the morphometry results document $<1 \%$ skeletal muscle fiber splitting. If skeletal muscular fibers splitting occurs $5 \%>$ of all skeletal muscular fibers, it is suggested to describe and calculate this in the final histopathological report.
\end{abstract}

\section{Key words}

Myopathology • Skeletal muscle fiber • Regeneration • Skeletal muscles

\section{Corresponding author}

Peter Makovický, Czech Centre for Phenogenomics, Institute of Molecular Genetic of the Czech Academy of Sciences, Průmyslová 595, 25250 Vestec, Czech Republic. E-mail: peter.makovicky@img.cas.cz

\section{Introduction}

Skeletal muscle regeneration is a highly orchestrated process and the factors that impact skeletal muscle structure, function and regeneration are of great importance and interest not only scientifically but also clinically. This means, skeletal muscles regeneration is in the interest of medical research (Kinter and Sinnreich 2014, Liu et al. 2018). Today skeletal muscle regeneration is studied at a high level including injury, development, factors contributing to regeneration, satellite cells, stem cells, the role of secreted factors and extracellular matrix remodelling (Baghdadi and Tajbakhsh 2018, Liu et al. 2019, Wosczyna et al. 2019). The results are important for applied research and especially for muscular dystrophies, which are characterized by atrophy, degeneration and fragmentation of skeletal muscle fibers with a partial or complete loss of contractility. It is well known, that smaller mechanical damage to skeletal muscle fibers can be accompanied by regeneration, but traumas that are more extensive are always followed by reparation with fibrosis (Filip et al. 2019, Holecek and Micuda 2017, Li et al. 2017, Morimoti et al. 2015, Ohno et al. 2019, Wens et al. 2019). Skeletal muscular fibers splitting with creating new skeletal muscular fibers are in this study present as possible activators or one ways to skeletal muscles regeneration (Antonio and Gonyea 1994). Most experiments are now carried out on rodents, due to their size, low breeding costs, high reproduction rate and stable genetic background. The mouse (Mus musculus, family Muridae) is the preferred laboratory animal in basic research. The International Mouse Phenotyping Consortium (IMPC) is an international effort by 19 research institutions to identify the function of every protein-coding gene in the mouse genome. Several 
objectives were identified (Meehan et al. 2017). Mice are produced and maintained on a $\mathrm{C} 57 \mathrm{BL} / 6 \mathrm{~N}$ genetic background with support mice derived from $\mathrm{C} 57 \mathrm{BL} / 6 \mathrm{NJ}$, C57BL/6NTac, or C57BL/6NCrl. All phenotyping centers across the world follow standards and generate seven females and seven male homozygotes, and compare them with seven female and seven male of the mentioned control mice. Veterinary pathologists play an important role, especially towards the end of the phenotyping process during necropsies, as well as evaluating histological slides of sampled organs. Crossstriated skeletal muscles are mandatory part of this sampling procedure. Here in this article, we suggest that the final histology results should describe two individual parameters related to the splitting of skeletal muscular fibers. First, to recognize and define skeletal muscular fiber splitting and second to calculate the percentage of split skeletal muscular fibers. This is descriptive light microscopy histopathological work and findings could be useful for the highly focused community in rodent histopathology. The objective of this study is to present data on the skeletal muscular fiber splitting in a wider set of proprietary material using C57BL/6NCrl mice skeletal muscles of $m$. rectus femoris ( $m$. quadriceps femoris).

\section{Material and Methods}

\section{Animal characteristics}

In this study $\mathrm{C} 57 \mathrm{BL} / 6 \mathrm{NCrl}$ mice were investigated and histologically examined in the Histopathology unit of the Czech Centre for Phenogenomics in Vestec as part of the phenogenomic screening. The Histopathology laboratory adheres to good laboratory practice (GLP) and all steps of mouse sample processing are according to standard operation procedures (SOP). All mice were sampled at 16 weeks of age. Femoral skeletal muscles of the right and left pelvic limbs were used for this purpose. Skeletal muscles ( $m$. rectus femoris ( $m$. quadriceps femoris)) from 500 (250 $q$ and 250 ふै) healthy C57BL/6NCrl mice were sampled during the autopsy. Mice were anesthetized using Isoflurane appropriately (Forane ${ }^{\circledR}$, AbbVie s.r.o., Prague, Czech Republic) and a dosing device. Subsequently, they were euthanized and skeletal muscles were sampled up to $20 \mathrm{~min}$. after euthanasia.

\section{Histological procedures}

The skeletal muscles were fixed for a minimum of 24 hours in $4 \%$ formalin solution. Material was excised and skeletal muscles were transversally oriented, and processed according to standardized protocols using autotechnicon Leica ASP 6P25 (Leica Biosystems Nussloch GmbH, Heidelberger, Germany). All samples were embedded into paraffin blocks using embedding station Leica EG 1150H (Leica Biosystems Nussloch $\mathrm{GmbH}$, Heidelberger, Germany). Samples were cut on rotary microtome Leica RM2255 (Leica Biosystems Nussloch GmbH, Heidelberger, Germany). Serial slices were placed onto standard slides (Knittel Glass Gmbh, Saksa, Germany) and stained with hematoxylin-eosin and integrated into permanent histological preparation with an automated staining station SYMPHONY system (Ventana Medical Systems, Inc. Tuscon, Arizona, USA).

\section{Samples evaluation}

Two slices per mouse were placed on each slide and analyzed. The prepared samples were evaluated as light-microscopic images obtained using the Carl Zeiss Axio Scope Al (Zeiss, Munchen, Germany) at magnifications 50x, 100x, 200x and 400x (Zeiss, Munchen, Germany). The slides were also evaluated using AxioScan.Z1 slide scanner (Zeiss, Munchen, Germany) and the percentage of split skeletal muscular fibers to all skeletal muscular fibers was quantified for each slide. The results were averaged and compared between male and female mice.

\section{Statistical analysis}

The morphometry results were analyzed using ANOVA and statistical computation was carried out using Statistix9 and IfoStat packages. Differences were declared significant at $\mathrm{p}<0.05$.

\section{Results}

Histological view with partially transversally, partially longitudinally sectioned skeletal muscles with sporadically visible solitary arranged hypertrophic spherical shape basophilic skeletal muscle fibers, which are mostly localized in the periphery of a primary muscle septum. Part of them are split to several miniature, shapeless, or triangular formations. Some have similar thicknesses compared to normal skeletal muscle fibers. The splitting mechanism is almost identical. An individual skeletal muscle fiber is visible, or there are few skeletal muscle fibers in close proximity to each other (Fig. 1A, and Fig. 1B). Mostly however, the sarcolemma remains preserved, and the skeletal muscular 
fiber split at one section into several thinner ellipsoid daughter units with several highlighted lighter nuclei. Subsequently, there is skeletal muscle fiber hypertrophy with nuclei movement at their periphery. Part of the split skeletal muscle fiber is phagocytosed and what remains is able to merge into one skeletal muscle fiber (Fig. 1C). The nuclei move from the periphery to the center of a split skeletal muscle fiber. Such skeletal muscle fibers are well recognizable due to the presence of bright, vesicular nuclei with prominent nucleoli when organized in chain formations and approach each other from opposite sides (Fig. 1D). The process continues until the nuclei interfere with each other at complete skeletal muscle fiber renewal. Consequently, the nuclei acquires a classical oval to semi-circular shape with subsarcolemal localization. In certain areas there is an interstitial reaction where the increasing content of epimysium surrounding the splitting skeletal muscular fibers is visible (Fig. 1E). In some individual cases, with an increasing content of split skeletal muscle fibers there are junctions between peripheral nerves and skeletal muscle fibers visible with focal axon degeneration (Fig. 1F). Others in the full material normal perimysium and normal several miniature capillaries are visible. No significant differences in the average percentage of skeletal muscular fiber regeneration, average percentage of hypertrophic skeletal muscular fibers and finally the average percentage of splitting skeletal muscular fibers were observed between female and male mice $(p<0.05)$.

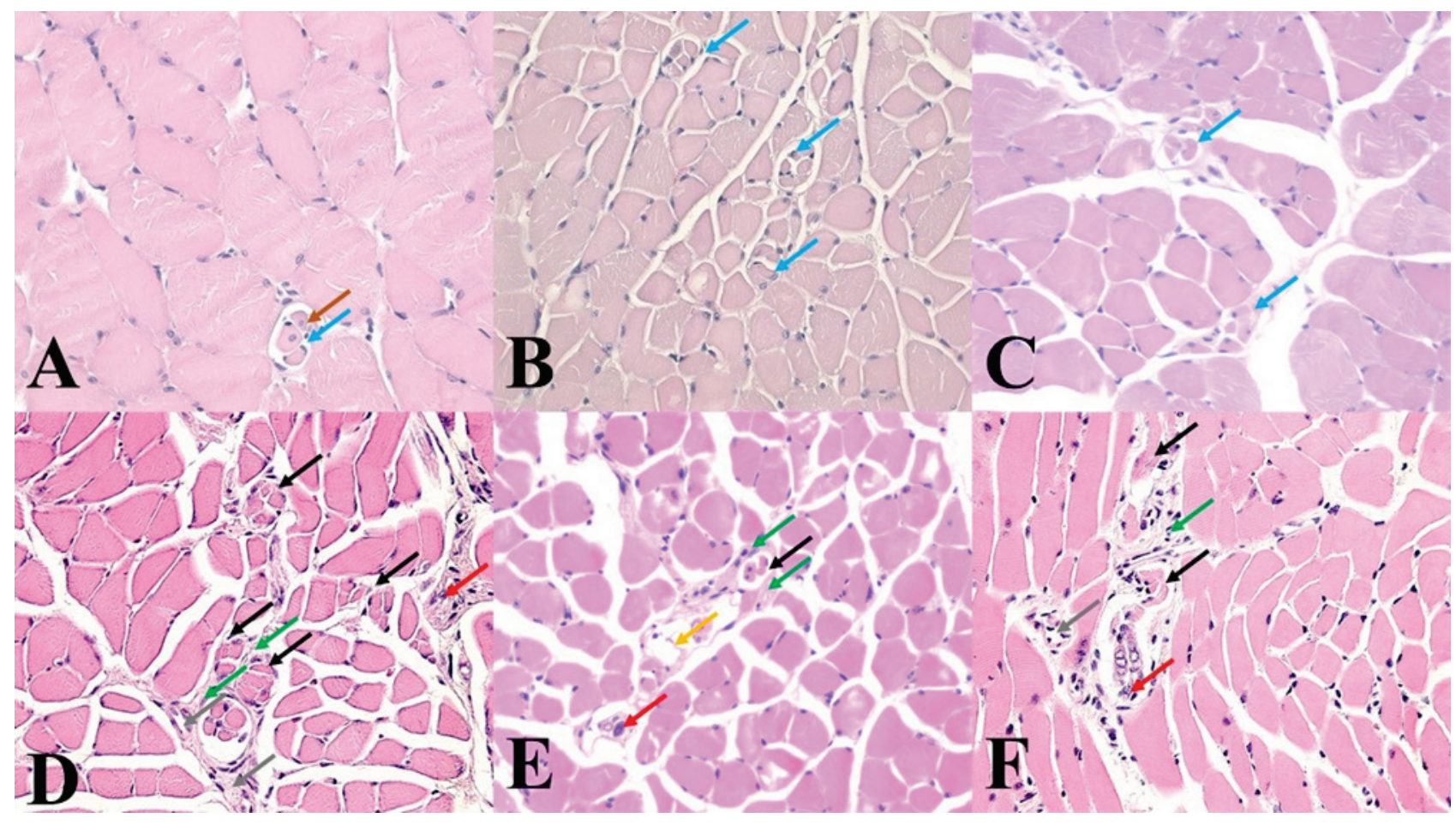

A) a cross-section of skeletal muscles with one well visible split skeletal muscular fiber. The brown arrow shows centrally localized nuclei and the blue arrow shows peripheral localized nuclei. Legend: HE: 400x. B) variably sized ellipsoid split skeletal muscular fibers. the blue arrows show nuclei localized at the periphery. Legend: HE: 400x. C) split skeletal muscular fibers. blue arrows show several ellipsoid formations with almost peripherally localized nuclei. Legend: HE: 400x. D) notably increased content of split skeletal muscle fibers (black arrows) with peripherally localized interstitial reaction (green arrows). The red arrow shows a periphery nerve and the grey arrow shows a capillary. E) view of the junction between periphery nerves (red arrow) and several split skeletal muscle fibres (black arrow) with focal skeletal muscle fiber necrosis (yellow arrow) and peripherally localized interstitial reaction (green arrows). F) another view of the junction between periphery nerves (red arrow) and several longitudinally sectioned split skeletal muscle fibers (black arrow) with periphery localised interstitial reaction (green arrows), the grey arrow shows a capillary.

\section{Discussion}

Skeletal muscle tissue damage and the following repair or regeneration are today intensively studied from many different views with high clinical importance. The regeneration of skeletal muscle fibers in skeletal muscles can occur in two ways; the origin of new skeletal muscle fibers derived from undifferentiated cells or autoregeneration of existing skeletal muscle fibers. The first option is to activate satellite cells that survive 
between fully differentiated skeletal muscle fibers. However, there are only limited possibilities (Forcina et al. 2019). The second variant consists in the splitting of existing skeletal muscle fibers. We have observed this phenomenon in our samples repeatedly and histologically there are differences between skeletal muscle fiber regeneration after injury, and skeletal muscle fiber splitting. An isolated splitting skeletal muscle fiber is a common finding, however if skeletal muscle fiber splitting exceeds $5 \%>$ value on evaluated slices, we believe this should be recorded and calculated in the final histopathology report. Here the veterinary pathologist can note if splitting is sufficient to compensate muscular defect, towards the relationships with normal skeletal muscle fibers. Other information about changes in the blood or lymphatic vessels, nerve fibers, the amount and type of connective tissue and necrosis should also be in the final report stated. In comparison to our previous work, where we observed the frequency of splitting skeletal muscle fibers in skeletal muscle of pigs. We found that with a pig's increasing age, a percentage increase in the occurrence of splitting skeletal muscle fibers is apparent, but this process has no importance in postnatal growth of skeletal muscle (Makovicky et al. 2015). Muscle splitting, proliferation of residual cellular islets, recombination of preserved skeletal muscle fibers and residual sarcoplasm have been observed histologically (Maxie 2016). On the other hand, it is not fully understood if the splitting of skeletal muscle fibers plays some role in the regeneration of damaged skeletal muscles, and is still a matter of research (Chen et al. 2019, Siles et al. 2019). There may be some differences in skeletal muscular fibers, including tissue responsiveness to internal and external influences. Therefore, we think that this phenomenon can be interpreted as a sign of muscular disruption. On the other hand, we here also accept an alternative of periphery nerve-skeletal muscles excitement exchange disorder. So finally skeletal muscle fibers splitting can be interpreted also as muscular fiber degeneration, followed by skeletal muscle fiber regeneration. For example, in standard veterinary bioptic practice, we practically do not see any skeletal muscular fibers splitting in domestic animals. On the other hand, using rodents, we had the opportunity to investigate multiple muscles at once in one histological preparation, comprising of a greater percentage of muscle tissue compared to the samples taken from the skeletal muscles of larger animals. Also in the scientific literature, there is an alternative to skeletal muscle fiber hyperplasia in adult skeletal muscles, but with significant differences in individual animal species (Brown 2000). By comparing our findings and conclusions with data in the scientific literature, we find partially similar and partially conflicting views. Generally, the hypothesis is that regeneration of skeletal muscles is dependent on the extent of skeletal muscle tissue damage. When the sarcoplasm and at least some of the nuclei remain preserved, the regeneration may be complete. The sarcoplasm increases its volume and produces multinuclear multinuclei protoplasmic islets that bind to become a syncytium. However, damage to muscle tissue with complete disruption of skeletal muscle fibers will always end with reparation. One study, for example, states that skeletal muscles regeneration takes place in two interdependent phases (Charge and Rudnicki 2004). This is a degenerative and regenerative phase. Necrosis of damaged skeletal muscle fibers along with the presence of inflammation are the main parts of the degenerative phase, which could also correspond with our findings when part of the split skeletal muscle fiber remains phagocytosed. In the regenerative phase, myogenic cells are activated in which the myofibrils are synthesized and arranged. At this stage, skeletal muscle fiber splitting was also observed, but this is explained as a result of insufficient fusion of regenerative skeletal muscle fibers (Cabral et al. 2008). Some of the works describing the splitting of skeletal muscle fibers are related to hypertrophic or even giant skeletal muscle fibers (Fazarin et al. 2002). On the contrary, we document that the splitting phenomenon is not bound to skeletal muscle fiber calibre. Here we believe that the thickness of skeletal muscle fibers is limited by the possibilities of transporting nutrients and oxygen to skeletal muscle fibers and vice versa. Murach et al. (2019) hypothesizes that fiber splitting is a non-pathological component of extreme loading and hypertrophy, which is primarily supported by evidence in animals, and proposes that the mechanisms and consequences of fiber splitting deserve further exploration. This partly correlates with our previous findings when we found that larger skeletal muscle fibers and especially hypertrophic, possibly giant skeletal muscle fibers are predisposed to splitting (Makovicky 2010). Conversely, the increased percentage of split skeletal muscle fibers ultimately endangers skeletal muscle function (Kiriaev et al. 2018). In any case, it is true that hypertrophic skeletal muscle fibers usually become subject to splitting. These can be splits into several thin to miniature basophilic elements, which 
sometimes markedly resemble isolated myoblasts, or myotubes with several bright vesicular nuclei and prominent nucleoli. However, it is a question of whether these are separate skeletal muscle fibers, which do not yet explain the mechanism of the formation of sarcolemma by splitting. There is a hypothesis that the original skeletal muscle fiber remains continuous, but in several places it was in fact split. It is not about the creation of separate skeletal muscle fibers, but only about sister skeletal muscle fibers within one. Here, we are inclined to the hypothesis of myofibril damage with their branching and subsequent disintegration of the hypertrophic skeletal muscle fiber (Faber et al. 2014). However, it is doubtful whether a part of the skeletal muscle fiber is able to regenerate, especially if part of the split skeletal muscular fiber remains phagocytosed. Another study was based on the assumption that hypertrophic skeletal muscle fibers are the result of muscle damage and the splitting of skeletal muscle fibers is the result of an older trauma, while others reflect the ongoing traumatic process (Eriksson et al. 2006). Contrary to us, the authors of this study have analyzed samples of the skeletal muscle of weightlifters, where the splitting is subject to particularly hypertrophic skeletal muscle fibers. It is well known that excessive muscular effort can lead to rhabdomyolysis and thus to the spectrum of degenerative changes in skeletal muscle fibers. The projected patterns of splitting hypertrophic skeletal muscle fibers could therefore respond to decaying skeletal muscle fibers. Microscopic changes here represent a continuum whose end stage is the removal of necrotic skeletal muscle fibers by phagocytosis.

\section{Conflict of interest}

There is no conflict of interest.

\section{Acknowledgement}

Supported by RVO 68378050, BIOCEV-CZ.1.05/ 1.1.00/02.0109, LM2015040, CZ.1.05/2.1.00/19.0395. Thanks to Czech Centre for Phenogenomics, Histopathology unit staff (Attila Juhász, Tereza Kalendová, MSc. Jan Kučera, MSc. Linda Kutlíková, MSc. Vanessa Pianta, MSc. Markéta Pícková, MSc. Ivana Pohorecká, Jana Zima, DiS.) for their excellent histological service. Special thanks to B.Sc. Miles Joseph Raishbrook for his English editorial assistance with this manuscript.

\section{References}

ANTONIO J. GONYEA WJ: Muscle fiber splitting in stretch-enlarged avian muscle. Med Sci Sports Exerc 26: 973-977, 1994. https://doi.org/10.1249/00005768-199408000-00007

BAGHDADI MB, TAJBAKHSH S: Regulation and phylogeny of skeletal muscle regeneration. Dev Biol 433: 200-209, 2018. https://doi.org/10.1016/j.ydbio.2017.07.026

CABRAL AJV, MACHADO V, FARINDA R, CABRITA A: Skeletal muscle regeneration: a brief review. Exp Pathol Health Sci 2: 9-17, 2008.

BROWN LE: Skeletal muscle fiber hyperplasia: Why it can or cannot occur in humans. Strength Cond J 22: 28-29, 2000. https://doi.org/10.1519/00126548-200004000-00008

ERIKSSON A, LINDSTROM M, CARLSSON L, THORNELL LE: Hypertrophic muscle fibers with fissures in powerlifters; fibers splitting or defect regeneration? Histochem Cell Biol 126: 409-417, 2006. https://doi.org/10.1007/s00418-006-0176-3

FABER RM, HALL JK, CHAMBERLAIN JS, BANKS GB: Myofiber branching rather than myofiber hyperplasia contributes to muscle hypertrophy in mdx mice. Skeletal Muscle 23: 10, 2014. https://doi.org/10.1186/20445040-4-10

FAZARINC G, CANDEK-POTOKAR M, URSIC M, VRECL M, POGACNIK A: Giant muscle fibres in pigs with different Ryr1 genotype. Anat Histol Embryol 31: 367-371, 2002. https://doi.org/10.1046/j.14390264.2002.00420.x

FILIP S, MOKRY J, FOROSTYAK O, DAYANITHI G: Analysis of Ca(2+) signaling mechanisms - our experience on the intercellular communication in muscle remodeling. Physiol Res 68: 325-328, 2019. https://doi.org/10.33549/physiolres.934082

FORCINA L, MIANO C, PELOSI L, MUSARO A: An overview about the biology of skeletal muscle Satellite cells. Curr Genomics 20: 24-37, 2019. https://doi.org/10.2174/1389202920666190116094736 
CHARGE SB, RUDNICKI MA: Cellular and molecular regulation of muscle regeneration. Physiol Rev 84: 209-238, 2004. https://doi.org/10.1152/physrev.00019.2003

CHEN F, ZHOU J, LI Y, ZHAO Y, CAO Y, WANG L, ZHANG Z, ZHANG B, WANG CC, CHEUNG TH, WU Z, WONG CC, SUN H, WANG H: YY1 regulates skeletal muscle regeneration through controlling metabolic reprogramming of Satellite cells. EMBO J 38: 99727, 2019. https://doi.org/10.15252/embj.201899727

HOLECEK M, MICUDA S: Amino acid concentrations and protein metabolism of two types of rat skeletal muscle in postprandial state and after brief starvation. Physiol Res 66: 959-967, 2017. https://doi.org/10.33549/physiolres.933638

KINTER J, SINNREICH M: Molecular targets to treat muscular dystrophies. Swiss Med Wkly 144: 13916, 2014. https://doi.org/10.4414/smw.2014.13916

KIRIAEV L, KUEH S, MORLEY JW, NORTH KN, HOUWELING PJ, HEAD SI: Branched fibers from old fasttwitch dystrophic muscles are the sites of terminal damage in muscular dystrophy. Am J Physiol Cell Physiol 314: C662-C664, 2018. https://doi.org/10.1152/ajpcell.00161.2017

LI XY, FU LL, CHENG HJ, ZHAO SH: Advances on microRNA in regulating mammalian skeletal muscle development. Yi Chuan 39: 1046-1053, 2017. https://doi.org/10.16288/j.yczz.17-112

LIU J, SAUL D, BOKER KO, ERNST J, LEHMAN W, SCHILLING AF: Current methods for skeletal muscle tissue repair and regeneration. BioMed Res Int 1: 1984897, 2018. https://doi.org/10.1155/2018/1984879

LIU X, ZENG Z, ZHAO L, CHEN P, XIAO W: Impaired skeletal muscle regeneration induced by macrophage depletion could be partly ameliorated by MGF injection. Front Physiol 10: 601, 2019. https://doi.org/10.3389/fphys.2019.00601

MAKOVICKY P: Histological study of giant fibres in skeletal muscles of pigs. Fleischwirt Int 25: 966-968, 2010.

MAKOVICKY P, MAKOVICKY P, LIPPAI R, SZIKSZ E, SAMASCA G: A harántcsíkolt izomrostok fejlödése és növekedése. (In Hungarian) Magy Allatorvosok 137: 559-567, 2015.

MAXIE G: Jubb, Kenedy, and Palmers Pathology of domestic animals. St. Louis, Elsevier 798, 2010.

MEEHAN TF, CONTE N, WEST DB, JACOBSEN JO, MASON J, WARREN J, CHEN CK, TUDOSE I, RELAC M, MATTHEWS P, et al.: Disease model discovery from 3,328 gene knockouts by The International Mouse Phenotyping Consortium. Nat Genet 8: 1231-1238, 2017. https://doi.org/10.1038/ng.3901

MORIMOTO Y, KONDO Y, KATAOKA H, HONDA Y, KOZU R, SAKAMOTO J, NAKANO J, ORIGUCHI T, YOSHIMURA T, OKITA M: Heat treatment inhibits skeletal muscle atrophy of glucocorticoid-induced myopathy in rats. Physiol Res 64: 897-905, 2015.

MURACH KA, DUNGAN CM, PETERSON CA, MCCARTHY JJ: Muscle fiber splitting is a physiological response to extreme loading in animals. Exerc Sport Sci Rev 47: 108-115, 2019. https://doi.org/ 10.1249/JES.0000000000000181

OHNO Y, EGAWA T, YOKOYAMA S, FUJAYA H, SUGIURA T, OHIRA Y, YOSHIOKA T, GOTO K: MENSassociated increase of muscular protein content via modulation of caveolin-3 and TRIM72. Physiol Res 68: 265-273, 2019. https://doi.org/10.33549/physiolres. 933992

SILES L, NINFALI C, CORTES M, DARLING DS, POSTIGO A: ZEB1 protects skeletal muscle from damage and is required for its regeneration. Nat Commun 10: 1364, 2019. https://doi.org/10.1038/s41467-019-08983-8

WENS I, DALGAS U, VERBOVEN K, KOSTEN L, STEVENS A, HENS N, EIJNDE BO: Impact of high intensity exercise on muscle morphology in EAE rats. Physiol Res 64: 907-923, 2015.

WOSCZYNA MN, KONISHI CT, PEREZ CARBAJAL EE, WANG TT, WALSH RA, GAN Q, WAGNER MW, RANDO TA: Mesenchymal stromal cells are required for regeneration and homeostatic maintenance of skeletal muscles. Cell Rep 27: 2029-2035, 2019. https://doi.org/10.1016/j.celrep.2019.04.074 


\title{
The Issue of Skeletal Muscle Growth and Regeneration
}

\author{
Ivan VARGA ${ }^{1}$, Zbyněk TONAR ${ }^{2}$, Ayman GHALLAB ${ }^{3,4}$, Lubos DANISOVIC ${ }^{5}$, Martin \\ KLEIN $^{1}$
}

${ }^{1}$ Institute of Histology and Embryology, Faculty of Medicine, Comenius University in Bratislava, Slovakia, ${ }^{2}$ Department of Histology and Embryology and Biomedical Centre, Faculty of Medicine in Pilsen, Charles University, Prague, Czech Republic, ${ }^{3}$ Department of Histology and Cell Biology, Faculty of Medicine, Zagazig University, Zagazig, Egypt, ${ }^{4}$ British University in Egypt, Cairo, Egypt, ${ }^{5}$ Institute of Medical Biology, Genetic and Clinical Genetic, Faculty of Medicine, Comenius University in Bratislava, Slovakia

Received May 4, 2020

\section{Comment on:}

PETER MAKOVICKÝ, PAVOL MAKOVICKÝ: Histological aspects of skeletal muscle fibers splitting of C57BL/6NCrl mice. Physiol Res 69: 291-296, 2020

\section{Corresponding author}

Ivan Varga, Institute of Histology and Embryology, Faculty of Medicine, Comenius University in Bratislava, Špitalska Street 24, 81372 Bratislava, Slovakia. E-mail: ivan.varga@fmed.uniba.sk

Dear Editor,

Skeletal muscle reparation and regeneration is indeed a very interesting issue from various perspectives. The interest of both the expert communities and lay public is explicable by the issue of skeletal muscle injuries in professional athletes, one of the leading causes of prolonged discontinuation of their active sport career. Comparably interesting is also the area of research focused on genetically determined muscular atrophies. For the above-mentioned reasons, we have read with great interest the paper "Histological aspects of skeletal muscle fibers splitting of C57BL/6NCrl mice" by Makovický and Makovický (2020).

What grabbed our attention the most is that the manuscript title refers to "muscle fibers splitting". However, the photomicrographs in the presented article show clearly distinguishable muscle spindles, which are normal components of the skeletal muscle. However, this is not the only problem of this paper.

Mammalian skeletal muscle is capable of regeneration, although this ability has its limits if the skeletal muscle injury is extensive and a certain regenerative threshold is reached (Liu et al. 2018). Muscle regeneration is based predominantly on the action of satellite cells (also called resident muscle stem cells) and is mainly controlled through the expression of extracellular matrix (ECM) proteins and various bioactive molecules. Satellite cells are a heterogeneous population of quiescent cells, which are arrested at an early stage of the myogenic program (Oprescu et al. 2020). In case of injury, they are activated by the effect of specific molecules (e.g. MRF4, myogenin, MyoD, and Myf5), they proliferate and undergo the process of differentiation into myoblasts (Zammit 2017). Consequently, myoblasts fuse with each other to produce multinucleate myotubes, which give rise to mature muscle fibers. The plasticity of ECM is imperative to the ability of satellite cells to become activated, for their differentiation and subsequent migration to the location of injury (Petrosino et al. 2019). The paper by Murach et al. (2019), also cited by the authors, suggests that muscle fiber splitting may occur physiologically as a satellite cell-independent process, however, largely as a response to extreme overload of a muscle. We have not found any mention of such approach applied to mice described by Makovický and Makovický (2020).

The principal problem and the main flaw of the 
article by Makovický and Makovický (2020) is that in the slides from murine limb skeletal muscle the authors failed to identify muscle spindles and confused them with dividing skeletal muscle fibers. Muscle spindles are present in large numbers in skeletal muscles and are the most frequently found sensory organs in the musculoskeletal tissues of mammalian limbs (Ellaway et al. 2015). Each individual skeletal muscle of the limb contains 25-114 muscle spindles (Banks 2006). Just as a matter of interest, we would like to add that human skeletal muscles contain 44000 muscle spindles in total (Voss 1971). It is not surprising, from the perspective of various functional roles of skeletal muscles, that each muscle should possess a characteristic proprioceptive innervation. Muscle spindle (fusus neuromuscularis) is the spindle-shaped intramuscular stretch receptor which is important in the regulation of muscle contraction. A single muscle spindle receives one or more sensory nerve fibers, whose endings are located more or less in the middle of a small bundle of specialized intrafusal muscle fibers. These intrafusal fibers also receive their own motor innervation, allowing for the phasic and tonic aspects of the sensory responses to be independently adjusted (Bewick and Banks 2015).

The microscopic structure of the muscle spindles in clearly visible in the photomicrographs published in the paper by Makovický and Makovický (2020), especially their Fig. 1 C-F contain typical examples of muscle spindles. For a comparison, we provide our own photomicrographs (our Fig. 1A-B). The muscle spindles are located inside the skeletal muscle and are surrounded by thin connective tissue capsule comprised of fibroblasts and delicate collagen fibers. After more precise examination, inner and outer layer (internal and external lamina) can be distinguished with a space between them filled with glycosaminoglycan-containing jelly-like fluid. The muscle spindle contains intrafusal muscle fibers (myofibrae intrafusales), which differ from the regular muscle fibers in several features: they are shorter and they have fewer myofibrils. Nuclear bag fibers have aggregated nuclei occupying the central region. Nuclear chain fibers possess multiple nuclei arranged in chains. The polar region contains muscle fibers with motor end plates, while the equatorial region contains annulospiral sensory nerve endings. Apparently, this typical microscopic structure, which is illustrated in most pregraduate histology textbooks (Balko et al. 2018, Ross and Pawlina 2016) as well as in histopathology manuals (Heffner and Balos 2007), was confused with the process of muscle fiber splitting in the paper by Makovický and Makovický (2020). Many scientific papers dealing with mammalian muscle spindles in more detail are available, demonstrating e.g. the spatial reconstruction, fiber typing, histochemistry, and electron microscopy of the intrafusal fibers (Thornell et al. 2015), their innervation patterns (Banks 2015), fusimotor activity (Ellaway et al. 2015), and more.
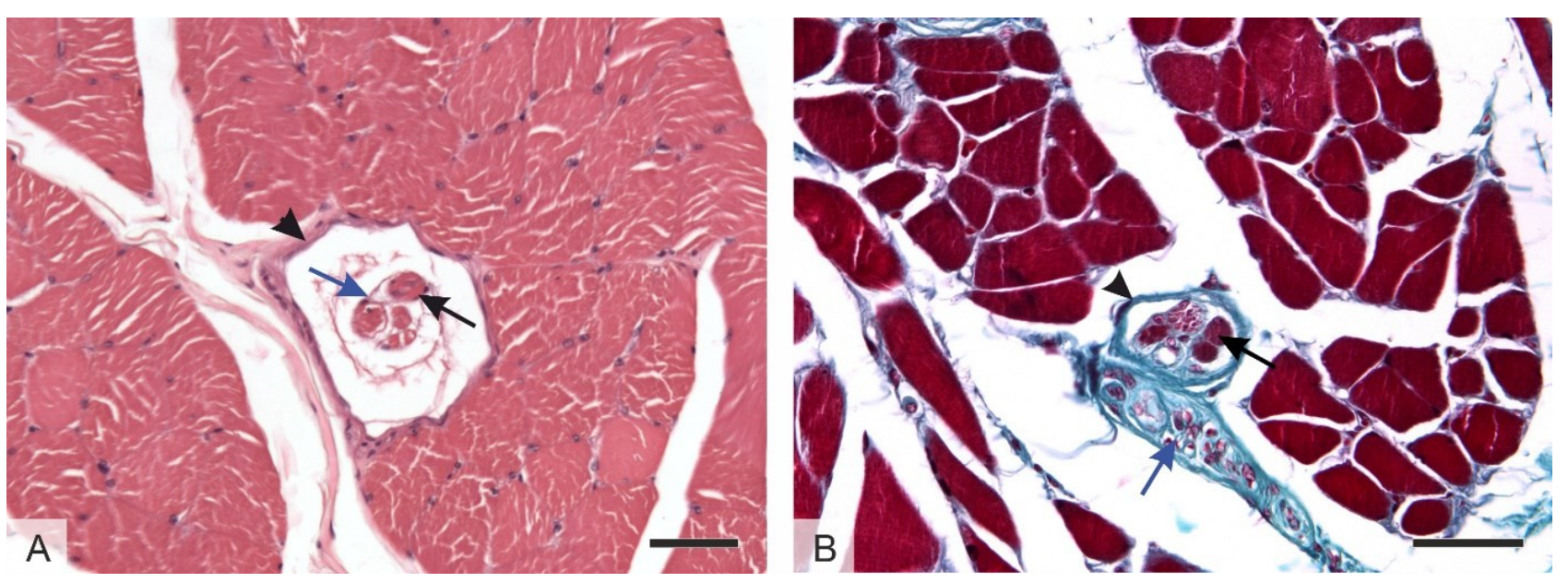

Fig. 1. Examples of mammalian muscle spindles as shown in routine preparations of skeletal muscles used in pregraduate Histology courses. (A) These stretch receptors are surrounded by an external capsule (black arrowhead). The internal capsule (blue arrow) contains intrafusal muscle fibers (black arrow). Interosseal muscles of the cat metacarpus, hematoxylin eosin stain, scale bar $50 \mu \mathrm{m}$. (B) External capsule (black arrowhead), intrafusal muscle fibers (black arrow), and unmyelinated nerve fibers. Human tongue, Verhoeff's iron hematoxylin and green trichrome stain, scale bar $50 \mu \mathrm{m}$. 
In the following points, we add several other comments, which put the finishing touches to the complex picture of this scientific article:

- "Methods: The morphometry results were analyzed using ..." The results don't contain any morphometry. What exactly did the authors measure? How was the countable event defined? How was the edge effect eliminated? What sampling strategy was applied? Did the authors quantify the diameter of muscle fibers, size of the nuclei, ratio between muscle tissue and interstitial connective tissue? Neither quantitative methods nor tools were described, what made the effort nonreproducible. As the authors probably counted various phenomena, the study cannot even be used for mapping the muscle spindles within the mouse rectus femoris muscle (Sato et al. 2007). Tschanz et al. (2014) summarized all the necessary requirements for planning, designing, and performing a successful morphometric study.

- "Results: ...hypertrophic spherical shape basophilic skeletal muscle fibers..." Skeletal muscle fibers are always acidophilic, never basophilic. This is due to the high content of mitochondria, myoglobin and smooth endoplasmic reticulum.

- "Results: There is skeletal muscle fiber hypertrophy with nuclei movement at their periphery”. Every skeletal muscle fiber has its nuclei located at the periphery. Moreover, without any scale bar, it is very hard for a reader to notice which muscle fiber is hypertrophic. No definition of hypertrophy was provided in the paper. Moreover, no reasons were provided why the fibers should undergo hypertrophy since all the mice were kept in similar environment with similar conditions, probably without any extreme physical activity.

- "Results: Part of the split skeletal muscle fiber is phagocytosed ..." This claim by the authors is not documented anywhere in the paper, even though the demonstration of macrophage presence is routinely performed, e.g. using antibodies against MAC 387 or CD68 or other monocyte/macrophage immunehistochemical markers. No macrophages are shown in the routine sections either.

- "Results: Splitting skeletal muscle fibers..." No markers of cell division and proliferation were used at all, although the study refers to "skeletal muscle regeneration".

- Results: The nuclei move from the periphery to the center of a split skeletal muscle fiber". Centrally located nuclei are found only in intrafusal muscle fibers inside the muscle spindles. Due to the main methodology flaw, the authors' description could probably match some of the intrafusal bag fibers with central aggregation of nuclei.

- "Results: Such skeletal muscle fibers are well recognizable due to the presence of bright, vesicular nuclei with prominent nucleoli ... (Fig. 1D)". The photomicrographs do not correlate with the narrative description of the results. With the magnification so low, and the pictures so blurred, it is hard to distinguish cell nuclei and almost impossible to distinguish mentioned nucleoli. Unfortunately, none of the presented photomicrographs display any of the "unique" findings the authors have observed, as they claim in the main text. In each picture, we only see muscle spindles, not dividing muscle fibers.

- "Results: ... junctions between peripheral nerves and skeletal muscle fibers visible with focal axon degeneration". What criteria of axonal degeneration were applied? How have the authors managed to observe focal axonal degeneration under a light microscope by using only such low magnifications and on top of that, by examining slides stained only with hematoxylin and eosin?

- "Results: No significant differences in the average percentage of skeletal muscular fiber regeneration, average percentage of hypertrophic skeletal muscular fibers ..." What method was used by the authors to study muscle fiber regeneration, which, under normal conditions, occurs via the activation of satellite cells? How have they managed to identify which muscle fibers were hypertrophic, when they have not mentioned any normative? These results are probably imaginative and not substantiated by own genuine research. No primary data are presented in the Results either in a graphical or in tabular form.

The aim of our criticism of the paper authored by Makovický and Makovický (2020) was to prevent the readers from being misinformed by a paper based on a major flaw such as confusing splitting muscle fibers with a stretch receptor.

\section{Acknowledgement}

Supported by the Slovak Research and Development Agency No. APVV-14-0032. 


\section{References}

BALKO J, TONAR Z, VARGA I, TONAR Z: Memorix Histology. Triton, Prague, 2018, pp 443.

BANKS RW: An allometric analysis of the number of muscle spindles in mammalian skeletal muscles. J Anat 208 : 753-768, 2006.

BANKS RW: The innervation of the muscle spindle: a personal history. J Anat 227: 115-135, 2015.

BEWICK GS, BANKS RW: Mechanotransduction in the muscle spindle. Pflugers Arch 467: 175-190, 2015.

ELLAWAY PH, TAYLOR A, DURBABA R: Muscle spindle and fusimotor activity in locomotion. J Anat 227 : 157-166, 2015.

HEFFNER RR, BALOS LL: Skeletal muscle. In: Histology for Pathologists. MILLS SE (ed.), Wolters Kluwer, Philadelphia, 2007, pp 203-204.

LIU J, SAUL D, BÖKER KO, ERNST J, LEHMAN W, SCHILLING AF: Current methods for skeletal muscle tissue repair and regeneration. Biomed Res Int 2018: 1984879, 2018.

MAKOVICKÝ P, MAKOVICKÝ P: Histological aspects of skeletal muscle fibers splitting of C57BL/6NCrl mice. Physiol Res 69: 291-296, 2020.

MURACH KA, DUNGAN CM, PETERSON CA, MCCARTHY JJ: Muscle fiber splitting is a physiological response to extreme loading in animals. Exerc Sport Sci Rev 47: 108-115, 2019.

OPRESCU SN, YUE F, QIU J, BRITO LF, KUANG S: Temporal dynamics and heterogeneity of cell populations during skeletal muscle regeneration. iScience 23: 100993, 2020.

PETROSINO JM, LEASK A, ACCORNERO F: Genetic manipulation of CCN2/CTGF unveils cell-specific ECMremodeling effects in injured skeletal muscle. FASEB J 33: 2047-2057, 2019.

ROSS MH, PAWLINA, W: Histology. A Text and Atlas with Correlated Cell and Molecular Biology, Wolters Kluwer, Philadelphia, 2016, pp 329-330.

SATO I, IMURA K, MIWA Y, IDE Y, MURATA M, SUNOHARA M: Distribution of slow muscle fiber of muscle spindle in postnatal rat masseter muscle. Okajimas Folia Anat Jpn 84: 99-105, 2007.

THORNELL LE, CARLSSON L, ERIKSSON PO, LIU JX, ÖSTERLUND C, STÅL P, PEDROSA-DOMELLÖF F: Fibre typing of intrafusal fibres. J Anat 227: 136-156, 2015.

TSCHANZ S, SCHNEIDER JP, KNUDSEN L: Design-based stereology: Planning, volumetry and sampling are crucial steps for a successful study. Ann Anat 196: 3-11, 2014.

VOSS H: Tabelle der absoluten und relativen Muskelspindelzahlen der menschlichen Skelettmuskulatur. Anat Anz 129: 562-572, 1971.

ZAMMIT PS: Function of the myogenic regulatory factors Myf5, MyoD, myogenin and MRF4 in skeletal muscle, satellite cells and regenerative myogenesis. Semin Cell Dev Biol 72: 19-32, 2017. 


\title{
Reply to the Issue of Skeletal Muscle Growth and Regeneration
}

\author{
Peter MAKOVICKÝ ${ }^{1}$, Pavol MAKOVICKÝ ${ }^{2}$ \\ ${ }^{1}$ Czech Centre for Phenogenomics, Institute of Molecular Genetic of the Czech Academy of \\ Sciences, Vestec, Czech Republic. ${ }^{2}$ Department of Biology, Faculty of Education, J. Selye \\ University, Komarno, Slovak Republic
}

Received May 15, 2020

\section{Corresponding author}

Peter Makovický, Czech Centre for Phenogenomics, Institute of Molecular Genetic of the Czech Academy of Sciences, Průmyslová 595, 25250 Vestec, Czech Republic. E-mail: peter.makovicky@img.cas.cz

Here, we would like to provide a short response to Letter to the Editor written by a respected human anatomists and histologists (Varga et al. 2020). The muscles of animals represent 40 to $50 \%$ of their body weight, and the greatest part of this mass consists of cross-striated skeletal muscles (Makovicky et al. 2009d). At present it is a subject of intensive veterinary research, as muscles represent one of the most important elements in human nutrition. In addition, they are at the centre of applied research especially for muscular dystrophies, which are histologically characterized by muscular fiber atrophy, fragmentation and necrosis. Therefore, muscular fiber regeneration is an important part of research, but reparation is only the final stage of skeletal muscle damage. It seems that gene mutations play major roles in muscular dystrophies. On the other hand, it can also be expressed that myopathology in veterinary medicine is still lacking sufficient knowledge, but we are certain that future discoveries about individual gene mutations will change the view of skeletal muscle disease classification. Several studies have concentrated on the pathophysiology of muscular dystrophies, and muscular fiber splitting is interpreted here as a degenerative process. From this, several experimental studies documented muscular fiber splitting as a result of intensive exercise (Antonio and Gonyea 1994, Ho et al. 1980, Sola et al. 1973) or also exercise and nutrition (Eriksson et al. 2006). Some authors are convinced that this process starts with skeletal muscle fiber hyperplasia and is followed by skeletal muscle fiber hypertrophy (Alway et al. 1989, Tamaki et al. 1992). One study documented muscle fiber splitting in the normal skeletal muscle of dogs without disease (Braund et al. 1982), or one necroptic study documented muscle fiber splitting in the skeletal muscles of horses (Valentine 2008). Other authors are convinced that muscular fiber can grow only to a limited thickness after they have split (Uhrín and Uhrín 1989). It was even proposed that mice are not the best animal species for potential muscular dystrophy therapeutic studies because results obtained in mice cannot always by replicated in humans (Duan et al. 2015). We are supposing that skeletal muscle fiber splitting can also be visualized in C57BL/6NCrl mice. Today, there are models for several phenotyping centers across the world. Taking into account that skeletal muscles are constantly sampled during phenotyping, we hold the opinion that it is important to monitor and report if there are some changes in skeletal muscle.

Muscle spindles are a persistent part of animal skeletal muscles, functioning as sensory receptors and playing an important role in muscle contraction. For example, there was a full presentation about skeletal muscle development at the International Congress of Slovak Anatomical Society and $44^{\text {th }}$ Lojda Symposium on Histochemistry, held in Bratislava. During the presentation, muscle spindles were also mentioned (Makovický et al. 2007d). In another International Congress on Anatomy and 49th Lojda Symposium on Histochemistry, held in Hradec Kralove, there was a full presentation showing the histological aspects of muscular 
fiber splitting, containing several detailed figures (Makovický et al. 2012). There have been several our presentations and/or articles dealing with the development of animal skeletal muscle (Kulíšek et al. 2004a, Kulíšek et al. 2004b, Makovický et al. 2007c, Makovický et al. 2009c), including the role of satellite cells or the impact of the MYF4 gene during skeletal muscle development (Makovický et al. 2006, Makovický et al. 2009a, Makovický et al. 2015). Special attention was given to giant fibers and muscular fiber splitting (Makovický et al. 2007a, Makovický and Makovický 2015), with several histological changes observed, including the influence of the RYRl gene and histological, histochemical changes in muscular fibers (Makovický et al. 2007b). A classification system for the splitting muscle fibers in the form of histological grade (G1-G4) was proposed and recommended for veterinary biopsy practice (Makovický et al. 2009b). Morphometric analyses were made and some histochemical properties of split skeletal muscles were identified (Makovický et al. 2010).

All the samples are derived from our IMPC (International Mouse Phenotyping Consortium) phenotyped mice. General information about the program is freely available. The consortium began work in 2011 with its first and immediate objective to generate a null mutant and undertake broad based phenotyping for every gene in the mouse genome. As of 2018, IMPC have completed 8,000 genes - more than a third of the mouse coding genome. Completing the null mutant resource will enable to define the complete catalogue of essential genes in the mammalian genome, as well as continue to elaborate and expand the view of the genome landscape for multiple disease areas. The phenotyping module at the Czech Center for Phenogenomics houses a comprehensive collection of tools for the physiological and morphological assessment of experimental mice and rats in a controlled SPF (specific pathogen-free) environment. All animal models and experiments used in study were ethically reviewed and performed in accordance with European directive 2010/63/EU and were approved by the Czech Central Commission for Animal Welfare. Each cohort contains prescribed mice, and from selected mice 30 female and 32 male organs are sampled, including two cytological smears. Our database currently contains 1219 (629 females; 590 males) C57BL/6NCrl mice. This study reflected our personal views and shows a selected portion of our results about skeletal muscles, but could prove to be useful for the highly focused community in rodent histopathology. Results document normal skeletal muscles, and other macroscopic, histological results will be applied to particular mutant cohort mice, or to full control mice, and may be published in a future article. From the 500 samples discussed, those that possess split muscle fibers make up less than $1 \%$, which on calculation is a negligible amount. If we were to compare this with the amount of muscle spindles in skeletal muscle, it is clear that there is a difference in their numbers, which would lead to a result of more than $1 \%$.

Table 1. Percentage average of mice with hypertrophic/splitting muscular fibers and percentage average of hypertrophic/splitting muscular fibers on each individual sample.

\begin{tabular}{lcccc}
\hline \multirow{2}{*}{ Signature } & \multicolumn{2}{c}{ MHSMF } & \multicolumn{2}{c}{ AHSMF } \\
& $\mathbf{2 5 0} \odot$ & $\mathbf{2 5 0} \oslash^{\Uparrow}$ & FSM $q$ & FSM \\
\hline$H M F$ & $<1 \%$ & $<1 \%$ & $<1 \%$ & $<1 \%$ \\
$S M F$ & $<1 \%$ & $<1 \%$ & $<1 \%$ & $<1 \%$ \\
\hline
\end{tabular}

MHSMF: percentage average of mice with hypertrophic and splitting muscular fibers, AHSMF: percentage average of hypertrophic and splitting muscular fibers on each individual sample, FSM: femoral skeletal muscles, HMF: percentages average of hypertrophic muscular fibers, SMF: percentages average of splitting muscular fibers.

For analysis, slides with hypertrophic or splitting muscular fibers were scanned using a Carl Zeiss Axio Scope A1 (Zeiss, Germany), which allows morphometry analysis (Kučera 2018). The average percentage of hypertrophic and splitting muscular fibers was calculated. An independent reviewer recommended that we remove a table containing morphometric results from our paper (Makovický and Makovický 2020). Table 1 shows that hypertrophic and splitting muscular fibers are visible in less than $1 \%$ of all mice and less than $1 \%$ of each individual sample. Muscular spindles are also clearly visible in the skeletal muscle of C57BL/6NCrl Mice. We acknowledge the figure criticism, which correctly points to the presence of muscle spindles. It was an oversight not to mention muscular spindles in our results section, nor in our figure descriptions. However, it shall not be overlooked in our future works. It seems that splitting muscular fibers have different morphology during pathological conditions compared to spontaneous splitting. Even in normal muscles they are only occasionally visible, in one mutant cohort of mice we found an increasing number of split muscular fibers.

In our work, we do not discuss large-scale skeletal muscle regeneration or skeletal muscle 
degeneration, muscular fibers fragmentation and necrosis, which is accompanied by changes in the muscular fiber shape, color and fibrosis (Fig. 1A). What we do discuss is spontaneous muscular fiber splitting. Usually there is one hypertrophic muscular fiber (Fig. 1C), which undergoes splitting, but also one miniature splitting muscle fiber that is occasionally visible (Fig. 1D). Alternatively, the finding resembling an individual regenerating muscle fiber, which are histologically characterized by the presence of prominent cells, rows of internal myoblast nuclei and cytoplasmic basophilia (Nonneoplastic Lesion Atlas 2014). Figure 1E documents a row of internal vesiculated nuclei in regenerating muscle fibers. In accordance to Nonneoplastic Lesion Atlas (2014), which is a guide for standardizing terminology in toxicological pathology for rodents, they tend to retain their internal nuclei for some time, and this can serve as a marker for fibers that had previously undergone regeneration. Figure 1B documents muscular fibers with centrally localized nuclei. We are aware that the full view can be influenced by sampling and processing. Despite this, we believe that splitting muscle fiber are visible also near muscular spindles (Fig. 1F). This is our personal opinion, and we hope that our future work will shed more light on this issue. All the sampling materials, including sampling strategy, etc. strictly need to follow protocol. If we would like to make changes, it is only possible with additionally sampled material. Formol-parafin techniques in skeletal muscle histology often cause several artifacts and in order to minimize them, serial sections are requested. Our previous studies, and other external studies, dealing with skeletal muscles have utilized another fixative and alternative procedures, including additional staining for skeletal muscle evaluation. Certain changes in skeletal muscle fixation, sample processing and additional staining in mice phenotyping have been suggested several times by us. If clinics show signs of a musculoskeletal system disorder, or there are suspected changes in skeletal muscles, sampling from several muscle groups are always suggested. In addition, transversally oriented sections are recommended, so that the muscle fibers are visible in cross-section.

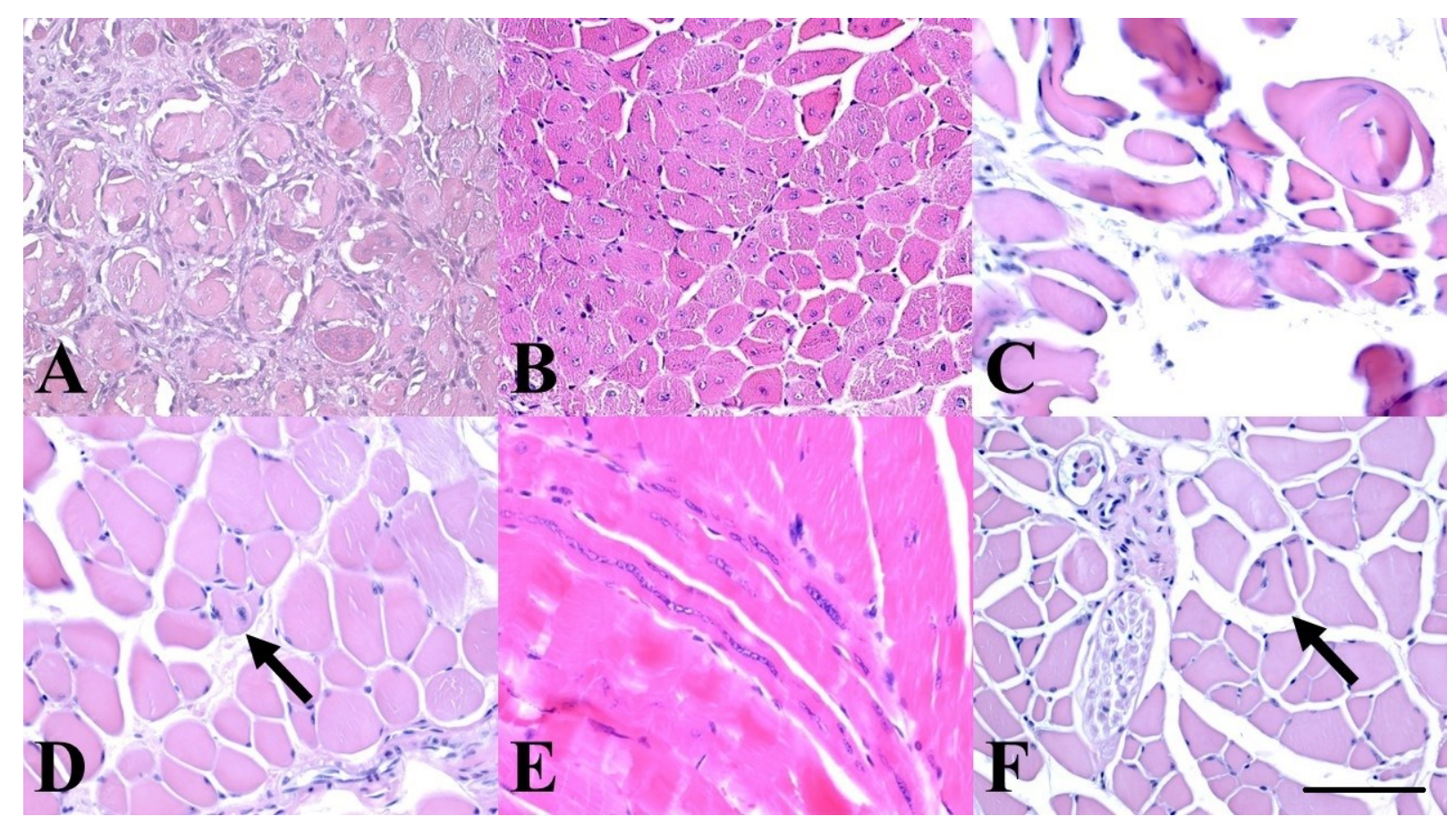

Fig. 1. Selected histological figures with description in the text. Legend: $A, B, C, D, E, F: H E: ~ 400 x$, scale bar: $50 \mu m$.

It is a generally accepted opinion that a set of histochemical and immunohistochemical stainings will distinguish particular cells and tissues within samples and to increase the accuracy of final diagnoses (Makovický and Švecová 2016). Today in Veterinary Pathology, most diagnoses are completed from hematoxylin-eosin staining
(Makovický 2015). Although our laboratory has a wider spectrum of additional special staining, it is possible to perform this appropriate staining only on a limited set of skeletal muscle samples. In our future work, a smaller sample number will be described with the appropriate additional staining. This approach is ongoing, especially 
in individual external studies. Myology is a separate field which requires its own laboratory and staff. Worldwide, there are several Veterinary Pathology laboratories with varying facilities. Most histological consultations or second reading are realized from hematoxylin-eosin staining. Here, it is not surprising that we can encounter many different interpretations on the same sample. Sample turnover requirements for evaluation exceed the time interval to receive results even in common veterinary biopsy practice.

Finally, we would like to thank Varga and coworkers for their Letter to the Editor, as we do also appreciate criticism. Everyone who shows a serious interest is welcomed to do so, and we are ready to cooperate within our capabilities to consult our findings. The value of our results has not decreased. It is only another view that has raised several questions, which can be expanded in future works concerning muscular fiber splitting. The common objective of research is to discuss the relevant topic and express different views of a common problem. In this way, cooperation between several specialists will be imperative to bring excellent results in the future, not only in skeletal muscle research.

\section{References}

ALWAY SE, WINCHESTER PK, DAVIS ME, GONYEA WJ: Regionalised adaptations and muscle fiber proliferation in stretch-induced enlargement. J Appl Physiol 66: 771-781, 1989.

ANTONIO J. GONYEA WJ: Muscle fiber splitting in stretch-enlarged avian muscle. Med Sci Sports Exerc 26: $973-$ 977, 1994.

BRAUND KG, MCGUIRE JA, LINCOLN CE: Observation on normal skeletal muscle of mature dogs: a cytochemical, histochemical, and morphometric study. Vet Pathol 19: 577-595, 1982.

HO KW, ROY RR, TWEEDLE CD, HEUSNER WW, VAN HUSS WD, CARROW RE: Skeletal muscle fiber splitting with weight-lifting exercise in rats. Am J Anat 157: 433-440, 1980.

DUAN D: Duchenne muscular dystrophy gene therapy in the canine model. Hum Gene Ther Clin Dev 26: 57-69, 2015.

ERIKSSON A, LINDSTROM M, CARLSSON L, THORNELL LE: Hypertrophic muscle fibres with fissures in powerlifters: fiber splitting or defect regeneration? Histochem Cell Biol 26: 409-417, 2006.

KUČERA J: Slide scanning technology. Phenogenomic Newsletter 2: 15-17, 2018.

KULÍŠEK V, MAKOVICKÝ P, VAVRIŠÍNOVÁ K: Some aspects of prenatal and postnatal growth of striated muscles of domestic animals. In: Book of Abstracts from International Scientific Seminar: Topical task solved in agrofood sector. Nitra. 65-66, 2004a.

KULÍŠEK V, MAKOVICKÝ P, MLYNEK J, BOBČEK B: Influences on the growth and development of cross striated skeletal muscles. (In Slovak) In: Sborník příspěvků: Aktuální otázky produkce jatečných zvírat. Brno, 32-36, 2004 b.

MAKOVICKÝ P: Histological study of giant fibres in skeletal muscles of pigs. Fleischwirt Int 25: 966-968, 2010.

MAKOVICKÝ P: What does modern veterinary pathology have to offer? J Anim Vet Sci 1: 43-47, 2015.

MAKOVICKÝ P, MAKOVICKÝ P: Is postnatal growth of skeletal muscle in pigs performed by muscle fiber cleaving? (In Slovak) Veterináŕství 65: 709-717, 2015.

MAKOVICKÝ P, MAKOVICKÝ P: Histological aspects of skeletal muscle fibers splitting of C57BL/6NCrl mice. Physiol Res 69: 291-296, 2020.

MAKOVICKÝ P, ŠVECOVÁ I: Veterinary pathology: the past, present and the future. Phenogenomic Newsletter 2: 22-23, 2016.

MAKOVICKÝ P, KULÍŠEK V, MLYNEK J, HAŠČÍK P: Influence of the transverse striations of skeletal tissues on the growth of farm animals (review). Slov J Anim Sci 39: 218-225, 2006.

MAKOVICKÝ P, MAKOVICKÝ P, KULÍŠEK V, DEBRECÉNI O, HAŠČÍK P: Histological analysis of size, structure and appearance of giant fibres in skeletal muscles of pigs. Folia Vet 51: 5-8, 2007a.

MAKOVICKÝ P, MAKOVICKÝ P, LEVKUT M, CHRENKOVÁ M, KULÍŠEK V, JÍLEK F: Histopathological and genetic aspects of stress syndrome of the skeleton musculature of pigs with resulting PSE meat. Folia Vet 51: $3-4,2007 b$. 
MAKOVICKÝ P, MAKOVICKÝ P, KULÍŠEK V: Effects of Genetic Factors on Genesis and Growth of Striated Skeletal Muscular Tissues. (In Slovak) Cesk fyziol 56: 15-21, 2007c.

MAKOVICKÝ P, MAKOVICKÝ P, KULÍŠEK V, ŠŤASTNÝ P, BUČKO O: The development and histogenesis of the striated skeletal muscles of pigs. In: Programme and Abstract Book of the 41 st International Congress of Slovak Anatomical Society and $44^{\text {th }}$ Lojda Symposium on Histochemistry: MORPHOLOGY 2007. 65, 2007d

MAKOVICKÝ P, MAKOVICKÝ P, KAČÁNIOVÁ M, PAVLIČOVÁ S, HAŠČÍK P: Histochemical analysis of skeletal muscular tissues of pigs according to genotype MYF 4. Arch Tier/Arch Anim Breed 52: 395-401, 2009a.

MAKOVICKÝ P, MAKOVICKÝ P, CHRENKOVÁ M: Histopathological aspects of giant fibres in selected muscles of the pig. Isr J Vet Med 64: 31-35, 2009b.

MAKOVICKÝ P, MAKOVICKÝ P, LEVKUT M, LEVKUT M, VRTKOVÁ I: Histological and morphometrical parameters of the skeletal muscle development in pigs. Sci Agric Bohem 40: 121-129, 2009c.

MAKOVICKÝ P, MAKOVICKÝ P, KULÍŠEK V, KAČÁNIOVÁ M, PAVLIČOVÁ S, HAŠČÍK P: Morphometrical and histochemical study of the cross striated skeletal muscles of pigs. Slov J Anim Sci 42: 174-179, 2009d.

MAKOVICKÝ P, MAKOVICKÝ P, CHRENKOVÁ M, KULÍŠEK V: Our experiences with splitting of muscle fibers. In: Programme and Abstract Book of the MORPHOLOGY 2012 - 47th International Congress on Anatomy and 49th Lojda Symposium on Histochemistry. Hradec Králové, 90, 2012.

MAKOVICKÝ P, MAKOVICKÝ P, LIPPAI R, SZIKSZ E, SAMASCA G: The development and growth of muscular fibers of striated skeletal muscle. (In Hungarian) Magy Allatorvosok 137: 559-567, 2015.

Nonneoplastic Lesion Atlas. 2014 https://ntp.niehs.nih.gov/nnl/index.htm

SOLA OM, CHRISTENSEN DL, MARTIN AW: Hypertrophy and hyperplasia of adult chicken anterior latissimus dorsi muscles following stretch with and without denervation. Exp Neurol 41: 76-100, 1973.

TAMAKI T, UCHIYAMA S, NAKANO S: A weight-lifting exercise model for inducing hypertrophy in the hindlimb muscles of rats. Med Sci Sports Exerc 24: 881-886, 1992.

UHRÍN P, UHRÍN V: Meat production in terms of structural and functional properties of muscles. (In Slovak) Nitra: VUŽV, 82, 1989.

VALENTINE BA: Pathologic findings in equine muscle (excluding polysaccharide storage): a necroptic study. J Vet Diagn Invest 20: 572-579, 2008.

VARGA I, TONAR Z, GHALLAB A, DANISOVIC L, KLEIN M: The issue of skeletal muscle growth and regeneration. Physiol Res 69: 545-548, 2020. 